\title{
Meta-Analysis Comparing Potent Oral P2Y 12 Inhibitors versus Clopidogrel in Patients with Atrial Fibrillation Undergoing Percutaneous Coronary Intervention
}

\author{
Matteo Casula ${ }^{1,2}$ (D) Federico Fortuni ${ }^{1,2} \cdot$ Marco Ferlini $^{3} \cdot$ Francesca Fabris $^{1,2} \cdot$ Luigi Oltrona Visconti $^{1,3} \cdot$ \\ Sergio Leonardi ${ }^{1,2}$
}

Published online: 8 September 2020

(c) The Author(s) 2020

\begin{abstract}
Background In patients with atrial fibrillation (AF) receiving percutaneous coronary intervention (PCI), current guidelines recommend against combining potent oral $\mathrm{P}_{2} \mathrm{Y}_{12}$ inhibitors (i.e. ticagrelor or prasugrel) with oral anticoagulant (OAC) therapy, but the evidence is limited.

Objective The aim of this meta-analysis was to compare the efficacy and safety of potent oral $\mathrm{P} 2 \mathrm{Y}_{12}$ inhibitors with clopidogrel in patients receiving OAC therapy for AF after a recent PCI.

Methods Electronic databases were searched for randomized controlled trials (RCT) reporting outcomes according to the $\mathrm{P}_{2} \mathrm{Y}_{12}$ inhibitor used. Major or clinically relevant non-major bleeding were the safety endpoints, while the efficacy outcomes were major adverse cardiovascular events (MACE). The potent oral $\mathrm{P}_{2} \mathrm{Y}_{12}$ inhibitors prasugrel and ticagrelor were compared with clopidogrel. A subgroup analysis was conducted to evaluate the differences between patients treated with dual antithrombotic therapy (DAT) versus triple antithrombotic therapy (TAT).

Results Four RCTs that included 10,057 patients were included in this analysis. Potent oral P2 $\mathrm{Y}_{12}$ inhibitors were associated with a significant increase in major or clinically relevant non-major bleeding compared with clopidogrel (risk ratio $[\mathrm{RR}] 1.30,95 \%$ confidence interval [CI] 1.06-1.59, $p=0.01$; number needed to harm 18, 95\% CI 12-36). This finding was consistent regardless of the concomitant antithrombotic therapy (DAT vs. TAT; $p=0.69$ ). The risk of MACE did not differ between potent oral $\mathrm{P} 2 \mathrm{Y}_{12}$ inhibitors and clopidogrel (RR 1.02, 95\% CI 0.57-1.82).

Conclusions In patients receiving OAC therapy for AF after a recent PCI, potent oral $\mathrm{P} 2 \mathrm{Y}_{12}$ inhibitors increase the risk of clinically relevant bleeding compared with clopidogrel, with no evident benefit in terms of MACE reduction.
\end{abstract}

Electronic supplementary material The online version of this article (https://doi.org/10.1007/s40256-020-00436-8) contains supplementary material, which is available to authorized users.

Matteo Casula

matt.casula@gmail.com

1 Coronary Care Unit and Laboratory of Clinical and Experimental Cardiology, Fondazione IRCCS Policlinico San Matteo, Viale Camillo Golgi 19, 27100 Pavia, Italy

2 Department of Molecular Medicine, University of Pavia, Pavia, Italy

3 Division of Cardiology, Fondazione IRCCS Policlinico San Matteo, Pavia, Italy

\section{Key Points}

The optimal antithrombotic regimen in patients with atrial fibrillation after a percutaneous coronary intervention has not been settled.

Our meta-analysis compared the efficacy and safety of potent oral P2 $\mathrm{Y}_{12}$ inhibitors versus clopidogrel.

Potent $\mathrm{P}_{2} \mathrm{Y}_{12}$ inhibitors increase bleeding risk, without any measured reduction of ischemic events. 


\section{Introduction}

Atrial fibrillation (AF) is the most common sustained cardiac arrhythmia, affecting over 30 million people worldwide [1]. Over $80 \%$ of all AF patients have a clear indication for oral anticoagulants (OACs) to prevent systemic thromboembolism [2]. Approximately 5-10\% of these patients develop the need for percutaneous coronary intervention (PCI) because of an acute or chronic coronary syndrome (CCS) [3]. Potent oral $\mathrm{P}_{2} \mathrm{Y}_{12}$ inhibitors (i.e. ticagrelor and prasugrel), in addition to aspirin, demonstrated a prevalent net clinical benefit compared with clopidogrel by reducing major adverse cardiovascular events (MACE) in patients treated with PCI for acute coronary syndromes (ACS), while increasing the risk of bleeding $[4,5]$. However, considering the higher risk of bleeding in patients concomitantly treated with OACs and aspirin [6], current European and North American guidelines recommend against the use of ticagrelor or prasugrel as part of triple antithrombotic therapy (TAT) with aspirin and an OAC [7-11]. The use of potent oral $\mathrm{P} 2 \mathrm{Y}_{12}$ inhibitors has been proposed as part of dual antithrombotic therapy (DAT) with an OAC in patients at moderate or high risk of stent thrombosis (ST) [11, 12]. Recommendations favoring clopidogrel over potent oral P2 $\mathrm{Y}_{12}$ inhibitors in patients treated with TAT are based on a low level of evidence derived from studies conducted in patients treated with a vitamin K antagonist (VKA) rather than a direct oral anticoagulant (DOAC) $[6,13,14]$. In the present meta-analysis, we explored the efficacy and safety of potent oral $\mathrm{P} 2 \mathrm{Y}_{12}$ inhibitors compared with clopidogrel in patients treated with OAC therapy (DOAC or VKA) for non-valvular $\mathrm{AF}$ after a recent PCI.

\section{Methods}

The present study was conducted following the principles of the Preferred Reporting Items for Systematic Reviews and Meta-Analyses (PRISMA) [15].

\subsection{Data Sources, Search Strategy and Eligibility Criteria}

We searched the MEDLINE, EMBASE, and Cochrane electronic databases to February 2020 for original randomized controlled trials (RCTs) published in the English language in peer-reviewed journals that compared efficacy and safety outcomes in patients treated with both OAC therapy for nonvalvular AF and antiplatelet therapy (APT) for recent PCI. Screened studies were considered eligible for inclusion if the outcomes were reported separately for patients treated either with potent oral $\mathrm{P} 2 \mathrm{Y}_{12}$ inhibitors or clopidogrel. The keywords searched included 'atrial fibrillation', 'AF', 'nonvalvular atrial fibrillation', 'oral anticoagulant', 'percutaneous coronary intervention' or 'antiplatelet therapy'. To ensure our review was complete, references of the included studies and relevant reviews identified through the search were also analyzed. The search and the study selection were conducted independently by two authors (MC and FFo) and any disagreements were solved by consensus.

\subsection{Data Extraction and Quality Assessment}

Data were extracted by the first author and were assessed for completeness and accuracy by a second investigator. The extracted data were collected in a dedicated electronic database and included study details (name, year of publication, design, inclusion and exclusion criteria, number of patients included, follow-up duration), selected patient characteristics, AF form (i.e. paroxysmal, persistent, or permanent), risk scores of systemic thromboembolism and bleeding $\left(\mathrm{CHA}_{2} \mathrm{DS}_{2}\right.$-VASc and HAS-BLED), ACS or CCS, and safety and efficacy outcomes. The overall quality of evidence for each outcome was assessed using the Grading of Recommendations, Assessment, Development and Evaluations (GRADE) approach. This approach classifies the quality of evidence as high, moderate, low, and very low, and considers the presence of risk of bias, indirectness of evidence, inconsistency, imprecision of effect estimates and potential publication bias [16]. Outcome-specific quality of evidence and the magnitude of effect are summarized in Table 3.

\subsection{Outcomes}

The primary outcome was a composite of major bleeding or clinically relevant non-major bleeding, according to the study definition. The main efficacy outcome was MACE, collected as per trial definition. The definitions of the outcomes used in each trial are presented in Table 1.

\subsection{Statistical Analysis}

Extracted data were analyzed using the open-source statistical softwares ProMeta 3 and Review Manager version 5.3 (Copenhagen: The Nordic Cochrane Centre, The Cochrane Collaboration, 2014). The heterogeneity across the included studies was evaluated using the Cochrane $Q$, Tau ${ }^{2}$, and $I^{2}$ statistics. The $I^{2}$ index describes the percentage of total variation across the studies that is due to heterogeneity rather than chance. $I^{2}$ values of $25 \%, 50 \%$, and $75 \%$ were attributed to small, moderate, and large amounts of heterogeneity, respectively. Considering the possible clinical heterogeneity across the included studies, the effect size was estimated using a random-effect model as the risk ratio (RR) and relative $95 \%$ confidence interval (CI). For the endpoints that 


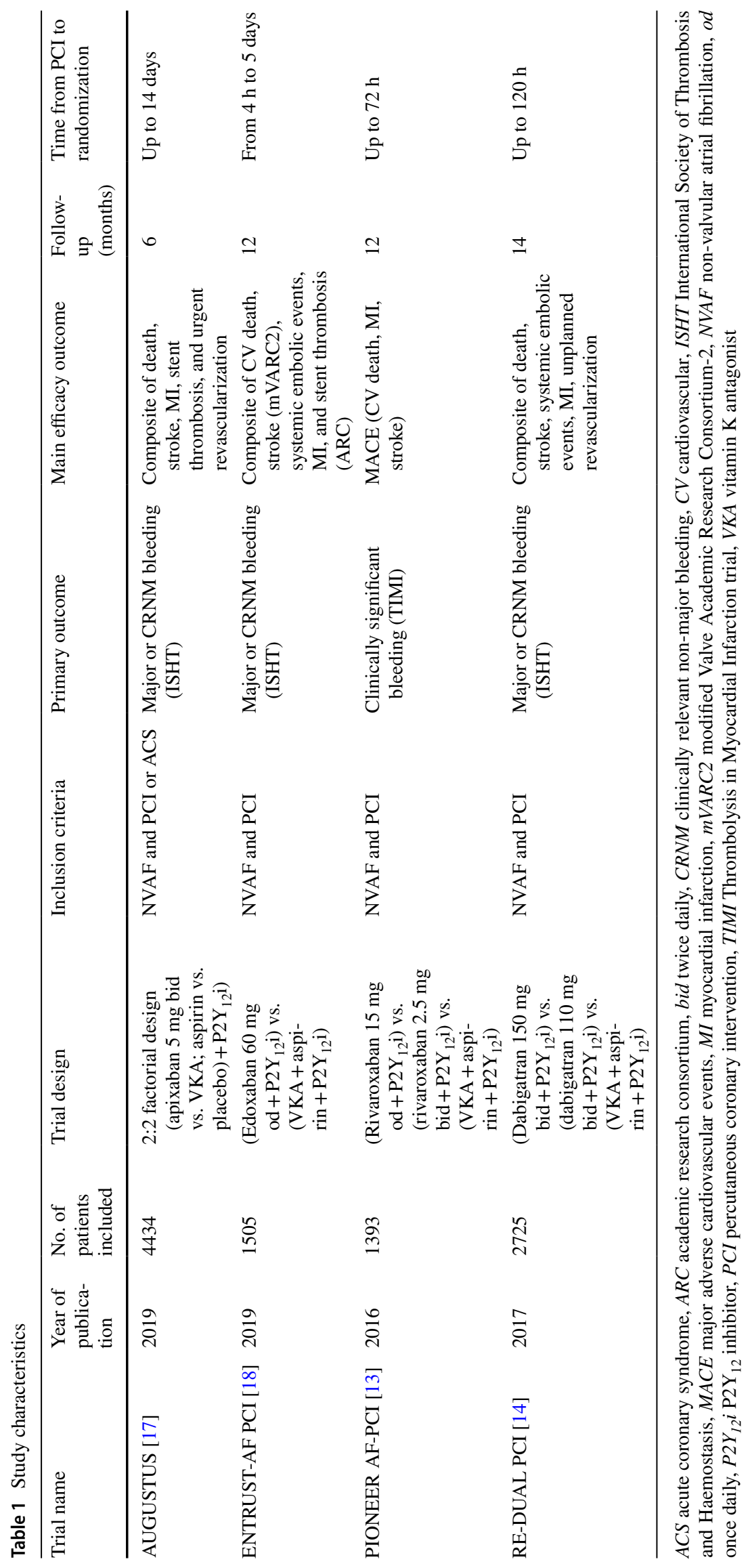


differed significantly in the two groups (i.e. $p$ value $<0.05$ ), the absolute risk reduction (ARR) or increase and number needed to treat (NNT) or number needed to harm (NNH) with relative $95 \%$ CI were calculated. A subgroups analysis was performed to assess the consistency of our results between patients treated with DAT (i.e. oral P2 $\mathrm{Y}_{12}$ inhibitor + OAC) and those treated with TAT (i.e. aspirin + oral $\mathrm{P}_{2} \mathrm{Y}_{12}$ inhibitor $\left.+\mathrm{OAC}\right)$. A leave-out-one sensitivity analysis was performed to evaluate the influence of each study on the pooled results. A univariate meta-regression was conducted to examine the impact of age, male sex, $\mathrm{CHA}_{2} \mathrm{DS}_{2}$-VASC and HAS-BLED scores, type of AF, prevalence of diabetes, prior stroke or systemic embolism, index event (i.e. ACS or elective PCI), and follow-up duration on the outcomes of interest (moderator effect). Moreover, we conducted a subgroup analysis to assess the potential moderator effect of the different bleeding definition used in the included studies (i.e. International Society of Thrombosis and Haemostasis, and Thrombolysis in Myocardial Infarction trial definitions).

\section{Results}

\subsection{Included Studies}

Overall, from the 2348 titles and abstracts identified through database searching, 23 full-text studies were selected and screened for eligibility. Four RCTs met our inclusion criteria and were considered for the final analysis (Fig. 1) [13, 14, 17, 18]. The arm of the PIONEER AF-PCI study treated with very-low-dose rivaroxaban was excluded from the analysis because rivaroxaban $2.5 \mathrm{mg}$ twice daily is not approved for the prevention of systemic embolism in patients with $\mathrm{AF}$ [19]. A total of 10,057 patients were included: 843 (8.4\%) patients were treated with a potent oral $\mathrm{P} 2 \mathrm{Y}_{12}$ inhibitor (ticagrelor $7.7 \%$ and prasugrel $0.7 \%$ ), and the remaining 9214 patients were treated with clopidogrel. The characteristics of both the included studies and the patients are presented in Tables 1 and 2, respectively. Mean age was $70.3 \pm 0.6$ years, and $73.8 \%$ were male. The mean follow-up period was $11 \pm 3.5$ months. The mean $\mathrm{CHA}_{2} \mathrm{DS}_{2}$-VASc score was $3.8 \pm 0.2$, the mean HAS-BLED score was $2.9 \pm 0.1$, and $47.8 \%$ of patients underwent PCI for ACS. The risk-of-bias assessment showed high quality for all included studies.

\subsection{Outcomes}

Potent oral P2 $\mathrm{Y}_{12}$ inhibitors were associated with a significant increase in the risk of major bleeding or clinically relevant non-major bleeding compared with clopidogrel (RR $1.30,95 \%$ CI 1.06-1.59, $p=0.01$; NNH 18, 95\% CI 12-36; moderate certainty of evidence (Fig. 2). Low certainty of evidence suggests no difference in the risk of MACE between the two groups (RR 1.02, 95\% CI 0.57-1.82) (Fig. 2). In the subgroup analyses, these findings were consistent regardless of the associated antithrombotic therapy [i.e. DAT vs. TAT; test for subgroup differences for bleeding: Chi square $=0.16$, degrees of freedom $[d f]=1, p=0.69$ (Fig. 3); test for subgroup differences for MACE: Chi square $=0.17, d f=1$, $p=0.68$ (Fig. 4)]. Among the patient- or study-related factors evaluated in the meta-regression analyses (i.e. age, male sex, $\mathrm{CHA}_{2} \mathrm{DS}_{2}$-VASC and HAS-BLED scores, type of AF, prevalence of diabetes, arterial hypertension, prior stroke or systemic embolism, index event, bleeding definition, and follow-up duration), and in the subgroup analysis (i.e. different bleeding definition), none showed a significant moderator effect on the safety or efficacy outcomes (electronic supplementary Tables S1 and S2, and Fig. S1). An overview of our findings is presented in Table 3.

\section{Discussion}

The main finding of this study-level meta-analysis is that in patients receiving OAC therapy for $\mathrm{AF}$ and with an indication to APT for a recent PCI, potent oral $\mathrm{P}_{2} \mathrm{Y}_{12}$ inhibitors (i.e. prasugrel or ticagrelor) compared with clopidogrel increase the risk of major bleeding or clinically relevant non-major bleeding without any measurable benefit on the reduction of MACE. These results were consistent in both TAT- and DAT-treated patients (i.e. with or without aspirin). Our results reinforce the safety concerns expressed by the international guidelines regarding the use of ticagrelor and prasugrel in patients treated with TAT [7-11]. Moreover, our data extend this warning to patients treated with DAT, thus covering the whole spectrum of patients who require OAC therapy for AF and APT for recent PCI, even with the use of DOAC.

On a mechanistic level, these findings could be explained by pharmacodynamic considerations. Ticagrelor and prasugrel achieve a faster, greater, and more consistent degree of $\mathrm{P} 2 \mathrm{Y}_{12}$ inhibition compared with clopidogrel, leading to stronger inhibition of platelet function [7]. As demonstrated by RCTs and observational studies [4, 5, 20], these pharmacological characteristics have a clinical impact, leading to an increased risk of bleeding events in patients treated with a potent oral $\mathrm{P} 2 \mathrm{Y}_{12}$ inhibitor compared with those treated with clopidogrel. Although in patients with ACS the increased bleeding risk is usually outweighed by a significant reduction in MACE [4, 5], our data confirm the safety concerns of this strategy in patients receiving OAC therapy beyond the clinical setting of PCI. Our analysis conducted in patients treated with OAC therapy for AF showed no significant differences in the risk of MACE between patients treated with potent oral $\mathrm{P} 2 \mathrm{Y}_{12}$ inhibitors and those treated with clopidogrel. This finding, combined with the demonstrated 

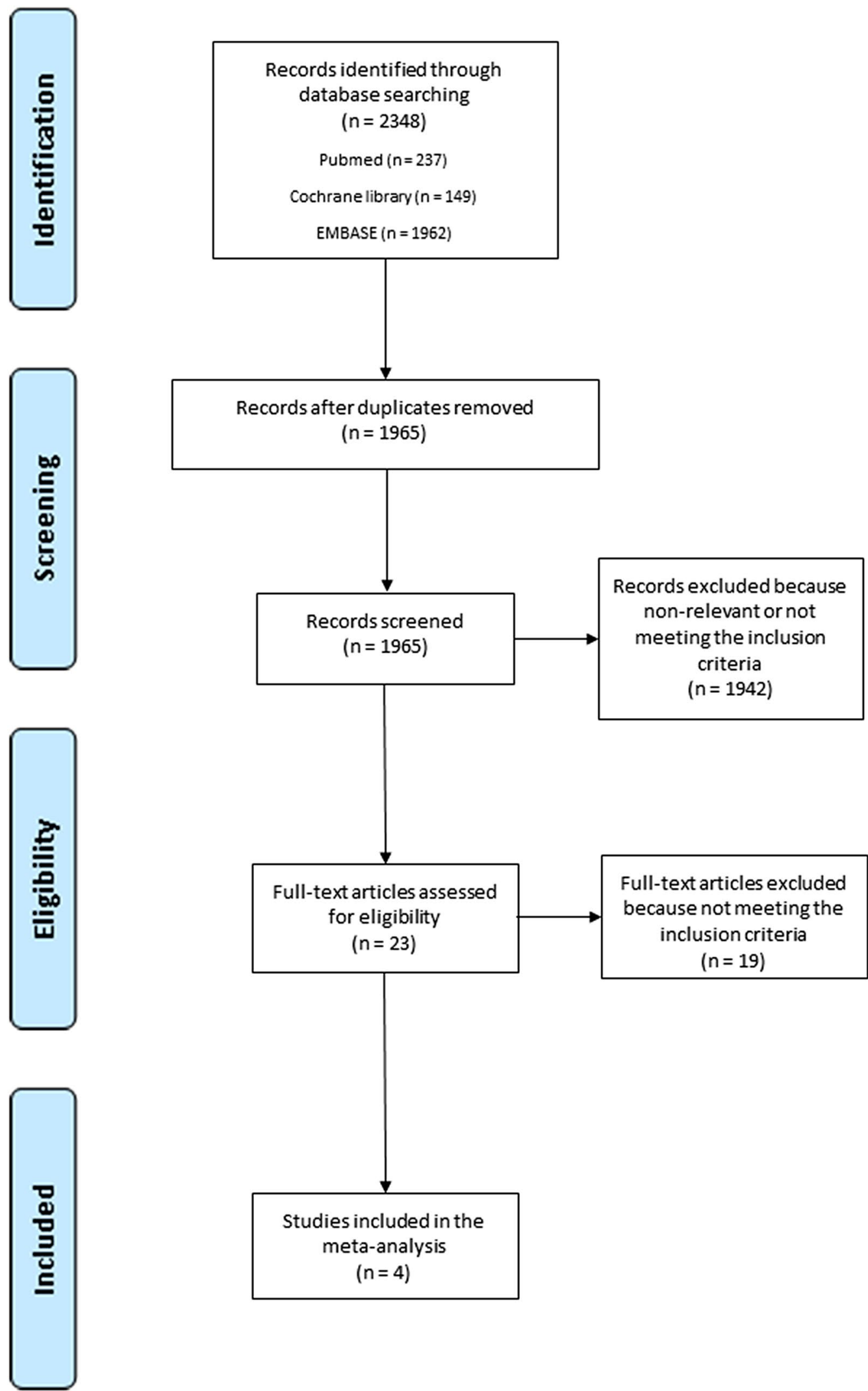

Fig. 1 Research strategy and study selection process

Studies included in the meta-analysis

$(n=4)$ 


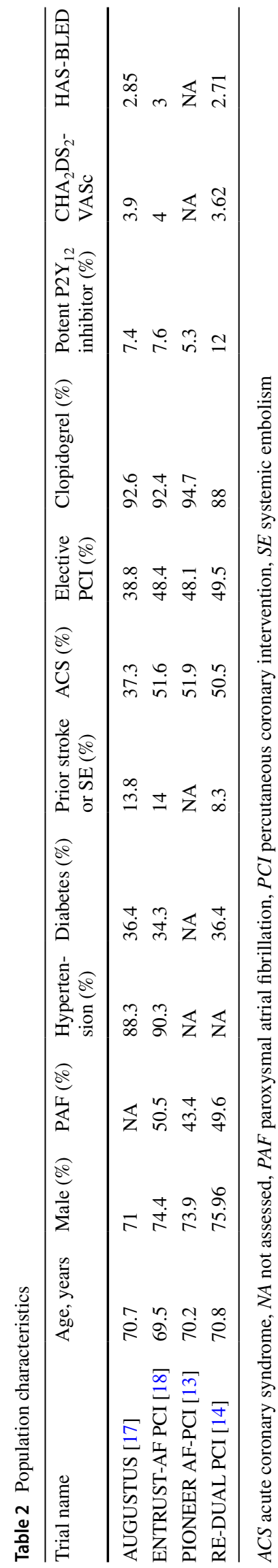

increase in bleeding risk (RR 1.30; NNH 18), leads to a negative risk/benefit profile for the use of potent oral $\mathrm{P} 2 \mathrm{Y}_{12}$ inhibitors in patients also treated with OAC therapy for AF.

The quality of evidence was moderate for the bleeding outcome and low for MACE. The main limiting factors were imprecision and inconsistency. Considering the wide CIs, inconsistency was relevant for both outcomes. In addition, the certainty of evidence for MACE was also lowered by imprecision, considering the high grade of heterogeneity and the relatively small sample size.

Several issues are still unsettled in the management of antithrombotic therapy in patients receiving OAC therapy for AF requiring APT for recent PCI. The evidence available has mainly focused on identifying the best anticoagulant agent (VKA vs. DOAC) and in comparing the DAT and TAT strategies. Recent published meta-analyses suggest a better clinical profile for DOAC over VKA, reporting a reduced risk of bleeding with a comparable risk of MACE. These findings were consistent when DOACs were considered both as single drugs and as a class [21, 22]. Another important unresolved issue is the timing of initiation and the duration of APT treatment. The time between PCI and the first intake of the randomized therapy ranged significantly across the included studies (from $4 \mathrm{~h}$ to 14 days), contributing to the persistence of a knowledge gap on this topic. Although showing a significant lower risk of bleeding in patients treated with DAT, a recent meta-analysis comparing the safety and efficacy outcomes of DAT versus TAT raised an important concern about the increase in the incidence of ST [23]. In this context, APT is the cornerstone treatment for the prevention of ST. Most STs occur within 30 days after PCI [24], and the risks of late and very late ST have declined considerably since the advent of new-generation drug-eluting stents [7,25]. Ticagrelor and prasugrel, in addition to aspirin, were demonstrated to be superior to clopidogrel in reducing ST in patients treated with PCI for ACS $[4,5]$. All studies included in our analysis were underpowered for efficacy endpoints and no data on ST are available for our comparison. This prevented us from addressing the potential effect of potent $\mathrm{P} 2 \mathrm{Y}_{12}$ inhibitors versus clopidogrel in reducing ST in patients also treated with OAC therapy for AF. Nonetheless, previous considerations combined with tailored and dynamic risk stratification, might lead to preserving space for the use of a potent oral $\mathrm{P} 2 \mathrm{Y}_{12}$ inhibitor in subgroups of patients with disproportionally high thrombotic risk after a complex PCI [25], and likely for a minimal duration. Nonetheless, further targeted studies are needed, and, considering the current evidence, clopidogrel should be preferred as the initial strategy in most patients. 


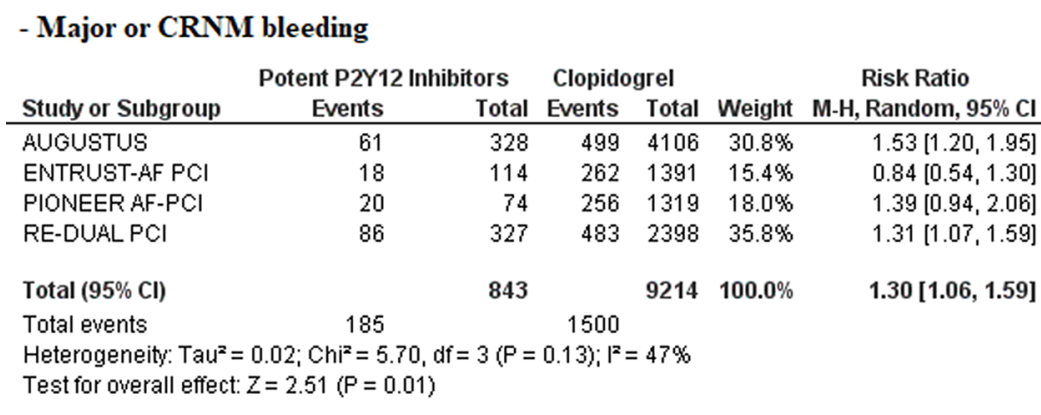

\section{- MACE

\begin{tabular}{lrrrrr} 
Study or Subgroup & Events & Total & Events & Total & Weight \\
\hline AUGUSTUS & 20 & 331 & 286 & 4165 & $42.1 \%$ \\
PIONEER AF-PCl & 1 & 74 & 76 & 1315 & $7.5 \%$ \\
RE-DUAL PCl & 61 & 327 & 309 & 2398 & $50.4 \%$ \\
& & 732 & & 7878 & $100.0 \%$ \\
Total (95\% Cl) & 82 & & 671 & \\
Total events & & & & \\
Heterogeneity: Tau $^{2}=0.16 ;$ Chi $^{2}=6.96, d f=2(P=0.03) ; I^{2}=71 \%$ &
\end{tabular} \\ Test for overall effect: $Z=0.08(P=0.94)$}

Fig. 2 Forest plots comparing major and CRNM bleeding and MACE between patients treated with potent oral $\mathrm{P}_{2} \mathrm{Y}_{12}$ inhibitors versus clopidogrel. CRNM clinically relevant non-major, MACE major
Risk Ratio , Random, 95\% Cl $0.88[0.57,1.37]$ $0.23[0.03,1.66]$ $1.45[1.13,1.86]$ $1.02[0.57,1.82]$

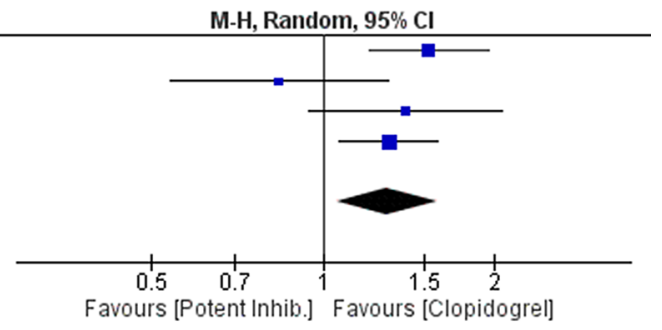

Favours [Potent Inhib.] Favours [Clopidogrel]
Risk Ratio M-H, Random, $95 \% \mathrm{Cl}$

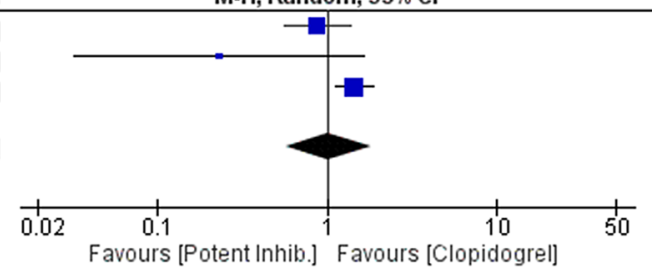

adverse cardiovascular events, $M-H$ Mantel-Haenszel, $C I$ confidence interval, $d f$ degrees of freedom, inhib inhibitors

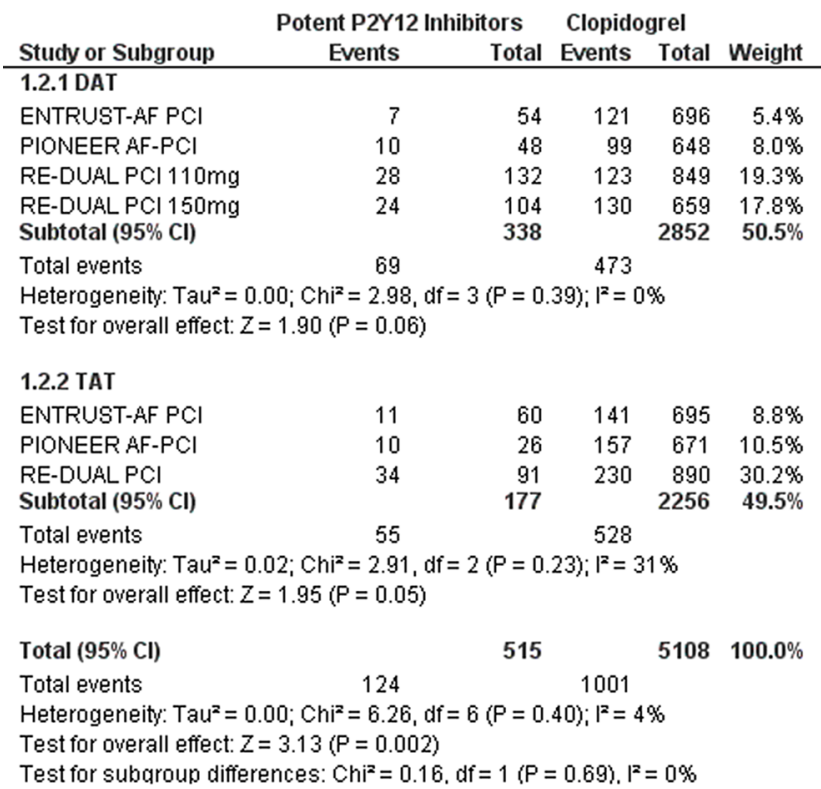

Fig. 3 Forest plot of subgroup analysis comparing major and CRNM bleeding according to antithrombotic strategy (DAT or TAT). CRNM clinically relevant non-major, $D A T$ dual antithrombotic therapy, $T A T$

\subsection{Limitations}

We must acknowledge some limitations. First, we had no access to the individual patient data and therefore conducted a study-level analysis. Second, treatment with
Risk Ratio Risk Ratio M-H, Random, $95 \% \mathrm{Cl}$
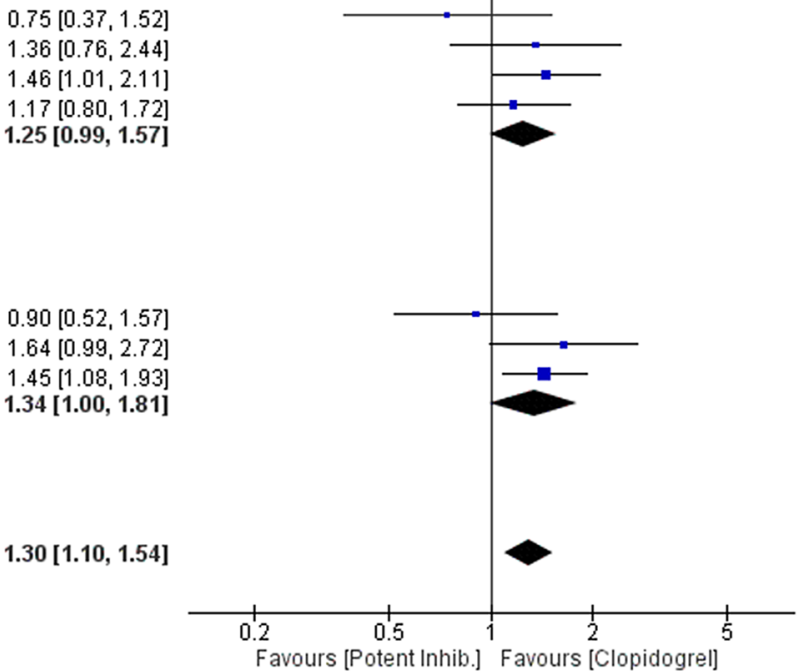

triple antithrombotic therapy, $M-H$ Mantel-Haenszel, $C I$ confidence interval, $d f$ degrees of freedom, inhib inhibitors

potent oral $\mathrm{P} 2 \mathrm{Y}_{12}$ inhibitors or clopidogrel was not randomized, which may introduce selection bias. Some conditions related to both ischemic and bleeding risk may not be uniformly distributed between the two studied strategies. It is possible that patients with lower bleeding risk 


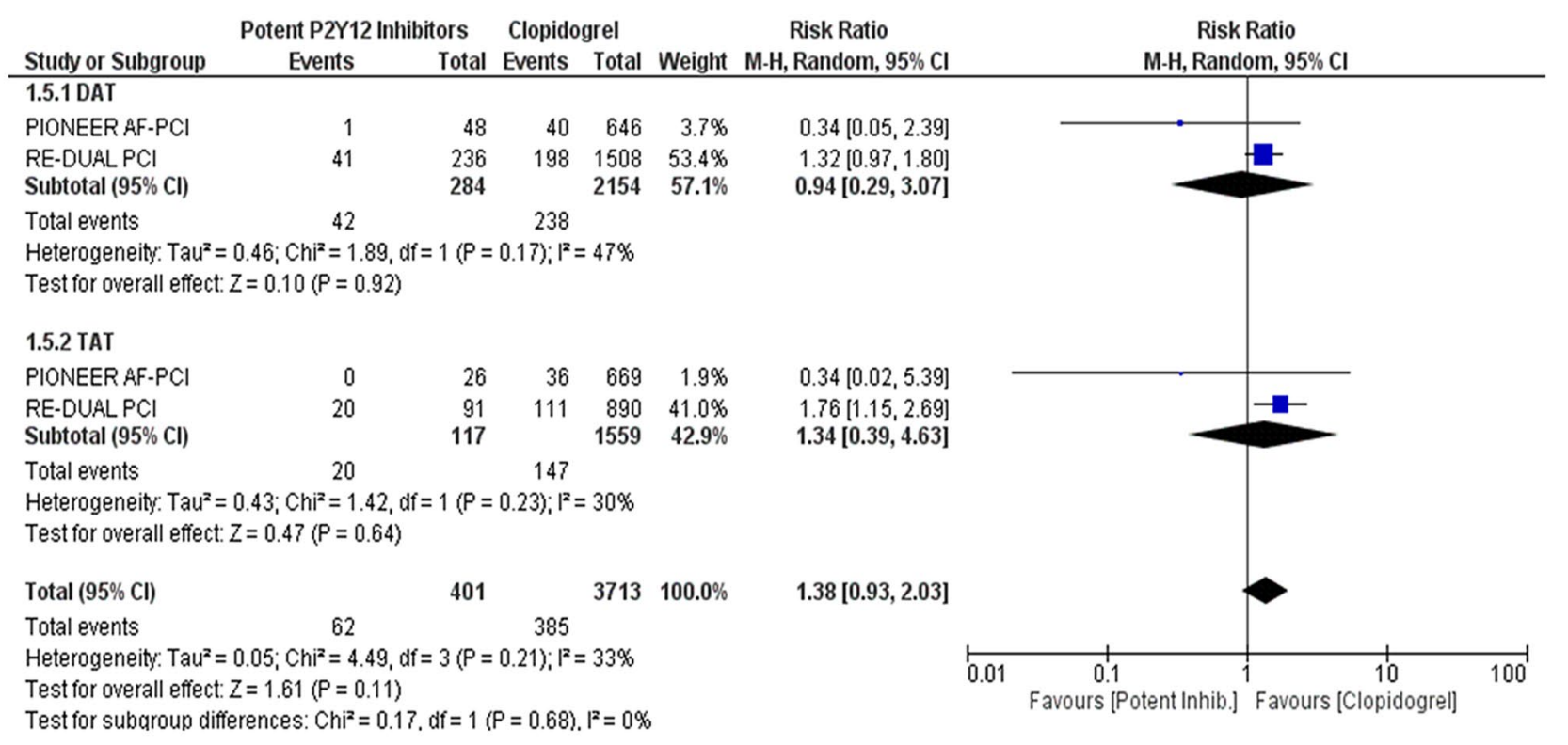

Fig. 4 Forest plot of subgroup analysis comparing MACE according to antithrombotic strategy (DAT or TAT). MACE major adverse cardiovascular events, DAT dual antithrombotic therapy, TAT triple

antithrombotic therapy, $M-H$ Mantel-Haenszel, $C I$ confidence interval, $d f$ degrees of freedom, inhib inhibitors

Table 3 Summary of findings

Potent $\mathrm{P}_{2} \mathrm{Y}_{12}$ oral inhibitors versus clopidogrel in patients with atrial fibrillation undergoing percutaneous coronary intervention

Patients or population: Patients treated with oral anticoagulants for AF undergoing PCI

Intervention: Potent $\mathrm{P}_{2} \mathrm{Y}_{12}$ oral inhibitors (i.e. ticagrelor or prasugrel)

Comparison: Clopidogrel

\begin{tabular}{llllll}
\hline Outcomes & Relative risk (95\% CI) & $\begin{array}{l}\text { Events in the } \\
\text { potent P2Y } \\
\text { arm (events/ } \\
\text { patients) }\end{array}$ & $\begin{array}{l}\text { Events in the } \\
\text { clopidogrel } \\
\text { arm (events/ } \\
\text { patients) }\end{array}$ & $\begin{array}{l}\text { No. of patients (no. } \\
\text { of study) }\end{array}$ & Certainty of evidence \\
\hline $\begin{array}{l}\text { Major bleeding or clinically } \\
\text { relevant non-major bleeding }\end{array}$ & $1.30(1.06-1.59)$ & $185 / 843$ & $1500 / 9214$ & $10,057(4)$ & Moderate $^{\mathrm{a}}$ \\
\begin{tabular}{l} 
MACE \\
\hline
\end{tabular} & $1.02(0.57-1.82)$ & $82 / 732$ & $671 / 7878$ & $8610(3)$ & Low $^{\mathrm{b}}$ \\
\hline
\end{tabular}

$A F$ atrial fibrillation, $C I$ confidence interval, $M A C E$ major adverse cardiovascular events, $P C I$ percutaneous coronary intervention

${ }^{a}$ Inconsistency: wide CIs

${ }^{\mathrm{b}}$ Inconsistency: wide CIs; imprecision: heterogeneity and small sample size

and higher ischemic risk were selected for treatment with potent oral $\mathrm{P}_{2} \mathrm{Y}_{12}$ inhibitors [26]. Third, some of the endpoints of interest were limited: the AUGUSTUS trial also included a small proportion of patients with medically managed ACS (23.9\%) and did not provide the data separately on the basis of the index event or on the basis of the treatment with DAT or TAT. The ENTRUST-AF PCI trial did not provide data on MACE. Moreover, the definition of MACE was not uniform across the included studies and the lack of specific data prevented us from analyzing the individual components of the composite endpoint. Fourth, due to the design of the included studies, there was significant heterogeneity across the studies: four different oral anticoagulant drugs with different safety/efficacy profiles [27]; the time between PCI and randomization ranged between $4 \mathrm{~h}$ and 14 days; the follow-up time ranged between 6 and 14 month; and we were unable to obtain outcomes data at a fixed follow-up time. 


\section{Conclusion}

In patients receiving $\mathrm{OAC}$ therapy for $\mathrm{AF}$ treated with APT for a recent PCI, moderate certainty of evidence suggests that potent oral $\mathrm{P} 2 \mathrm{Y}_{12}$ inhibitors increase the risk of clinically relevant bleeding compared with clopidogrel. This increase was observed regardless of the associated antithrombotic therapy, with probably no additive benefit in terms of reduction of ischemic events. Therefore, clopidogrel should be preferred over potent oral $\mathrm{P}_{2} \mathrm{Y}_{12}$ inhibitors in patients receiving OAC therapy for AF treated with APT for a recent PCI, regardless of the associated antithrombotic therapy.

\section{Declarations}

Funding No external funding was used in the preparation of this manuscript. Open access funding provided by Universit ̃̂ degli Studi di Pavia within the CRUI-CARE Agreement.

Conflicts of Interest Matteo Casula, Federico Fortuni, Marco Ferlini, Francesca Fabris, Luigi Oltrona Visconti and Sergio Leonardi declare they have no potential conflicts of interest that might be relevant to the contents of this manuscript.

Ethics Approval Not applicable.

Consent to Participate Not applicable.

Consent for Publication The publication of this paper has been approved by all co-authors, as well as by the responsible authorities, tacitly or explicitly, at the institute where the work has been carried out.

Availability of Data and Material Data will be made available by contacting the corresponding author.

\section{Code Availability Not applicable.}

Author Contributions MC conceived the idea for this work, designed the protocol, conducted the search and study selection processes, collected and analyzed the data, drafted this manuscript, and decided to submit it for publication. FF conducted the search and study selection processes, assessed the data extracted for completeness and accuracy, reviewed the statistical analysis, and critically revised the manuscript. All authors critically analyzed the data, revised the manuscript with important intellectual contributions, and approved its final version prior to submission.

Open Access This article is licensed under a Creative Commons Attribution-NonCommercial 4.0 International License, which permits any non-commercial use, sharing, adaptation, distribution and reproduction in any medium or format, as long as you give appropriate credit to the original author(s) and the source, provide a link to the Creative Commons licence, and indicate if changes were made. The images or other third party material in this article are included in the article's Creative Commons licence, unless indicated otherwise in a credit line to the material. If material is not included in the article's Creative Commons licence and your intended use is not permitted by statutory regulation or exceeds the permitted use, you will need to obtain permission directly from the copyright holder. To view a copy of this licence, visit http://creativecommons.org/licenses/by-nc/4.0/.

\section{References}

1. Chugh SS, Havmoeller R, Narayanan K, Singh D, Rienstra M, Benjamin EJ, et al. Worldwide epidemiology of atrial fibrillation. Circulation. 2014;129:837-47.

2. Lip GYH, Laroche C, Dan G-A, Santini M, Kalarus Z, Rasmussen $\mathrm{LH}$, et al. A prospective survey in European Society of Cardiology member countries of atrial fibrillation management: baseline results of EURObservational Research Programme Atrial Fibrillation (EORP-AF) Pilot General Registry. Europace. 2014;16:308-19.

3. Kirchhof P, Benussi S, Kotecha D, Ahlsson A, Atar D, Casadei B, et al. 2016 ESC Guidelines for the management of atrial fibrillation developed in collaboration with EACTS. Eur Heart J. 2016;37:2893-962.

4. Wallentin L, Becker RC, Budaj A, Cannon CP, Emanuelsson H, Held C, et al. Ticagrelor versus clopidogrel in patients with acute coronary syndromes. N Engl J Med. 2009;361:1045-57.

5. Wiviott SD, Braunwald E, McCabe CH, Montalescot G, Ruzyllo W, Gottlieb S, et al. Prasugrel versus clopidogrel in patients with acute coronary syndromes. N Engl J Med. 2007;357:2001-15.

6. Sarafoff N, Martischnig A, Wealer J, Mayer K, Mehilli J, Sibbing $\mathrm{D}$, et al. Triple therapy with aspirin, prasugrel, and vitamin $\mathrm{k}$ antagonists in patients with drug-eluting stent implantation and an indication for oral anticoagulation. J Am Coll Cardiol. 2013;61:2060-6.

7. Valgimigli M, Bueno H, Byrne RA, Collet J-P, Costa F, Jeppsson A, et al. 2017 ESC focused update on dual antiplatelet therapy in coronary artery disease developed in collaboration with EACTS. Eur Heart J. 2018;39:213-60.

8. Levine GN, Bates ER, Bittl JA, Brindis RG, Fihn SD, Fleisher LA, et al. 2016 ACC/AHA guideline focused update on duration of dual antiplatelet therapy in patients with coronary artery disease. J Thorac Cardiovasc Surg. 2016;152:1243-75.

9. Ibanez B, James S, Agewall S, Antunes MJ, Bucciarelli-Ducci C, Bueno H, et al. 2017 ESC Guidelines for the management of acute myocardial infarction in patients presenting with ST-segment elevation. Eur Heart J. 2018;39:119-77.

10. Roffi M, Patrono C, Collet J-P, Mueller C, Valgimigli M, Andreotti F, et al. 2015 ESC Guidelines for the management of acute coronary syndromes in patients presenting without persistent STsegment elevation. Eur Heart J. 2016;37:267-315.

11. Knuuti J, Wijns W, Saraste A, Capodanno D, Barbato E, FunckBrentano C, et al. 2019 ESC Guidelines for the diagnosis and management of chronic coronary syndromes. Eur Heart J. 2020;41:407-77.

12. Braun OÖ, Bico B, Chaudhry U, Wagner H, Koul S, Tydén P, et al. Concomitant use of warfarin and ticagrelor as an alternative to triple antithrombotic therapy after an acute coronary syndrome. Thromb Res. 2015;135:26-30.

13. Gibson CM, Mehran R, Bode C, Halperin J, Verheugt FW, Wildgoose $\mathrm{P}$, et al. Prevention of bleeding in patients with atrial fibrillation undergoing PCI. N Engl J Med. 2016;375(25):2423-34.

14. Cannon CP, Bhatt DL, Oldgren J, Lip GYH, Ellis SG, Kimura T, et al. Dual antithrombotic therapy with dabigatran after PCI in atrial fibrillation. N Engl J Med. 2017;377:1513-24.

15. Moher D, Liberati A, Tetzlaff J, Altman DG. Preferred reporting items for systematic reviews and meta-analyses: the PRISMA statement. PLoS Med. 2009;6:e1000097.

16. Langendam MW, Akl EA, Dahm P, Glasziou P, Guyatt G, Schünemann HJ. Assessing and presenting summaries of evidence in Cochrane Reviews. Syst Rev. 2013;2:81.

17. Lopes RD, Heizer G, Aronson R, Vora AN, Massaro T, Mehran $\mathrm{R}$, et al. Antithrombotic therapy after acute coronary syndrome or PCI in atrial fibrillation. N Engl J Med. 2019;380:1509-24. 
18. Vranckx P, Valgimigli M, Eckardt L, Tijssen J, Lewalter T, Gargiulo $\mathrm{G}$, et al. Edoxaban-based versus vitamin $\mathrm{K}$ antagonistbased antithrombotic regimen after successful coronary stenting in patients with atrial fibrillation (ENTRUST-AF PCI): a randomised, open-label, phase 3b trial. Lancet. 2019;394:1335-43.

19. Fda US. XARELTO (Rivaroxaban): prescribing information. White Oak: US FDA; 2017.

20. Xin Y, Zhang H, Li Y, Guan Q, Guo L, Gao Y, et al. Efficacy and safety of ticagrelor versus clopidogrel with different dosage in high-risk patients with acute coronary syndrome. Int J Cardiol. 2017;228:275-9.

21. Eyileten C, Postula M, Jakubik D, Toma A, Mirowska-Guzel D, Patti G, et al. Non-vitamin K oral anticoagulants (NOAC) versus vitamin K antagonists (VKA) for atrial fibrillation with elective or urgent percutaneous coronary intervention: a meta-analysis with a particular focus on combination type. J Clin Med. 2020;9(4):1120. https://doi.org/10.3390/jcm9041120.

22. Al Said S, Alabed S, Kaier K, Tan AR, Bode C, Meerpohl JJ, et al. Non-vitamin K antagonist oral anticoagulants (NOACs) post-percutaneous coronary intervention: a network meta-analysis. Cochrane Database Syst Rev. 2019;12(12):CD013252. https://doi. org/10.1002/14651858.cd013252.pub2.

23. Gargiulo G, Goette A, Tijssen J, Eckardt L, Lewalter T, Vranckx $\mathrm{P}$, et al. Safety and efficacy outcomes of double vs. triple antithrombotic therapy in patients with atrial fibrillation following percutaneous coronary intervention: a systematic review and meta-analysis of non-vitamin $\mathrm{K}$ antagonist oral anticoagulantbased randomiz. Eur Heart J. 2019;40(46):3757-67. https://doi. org/10.1093/eurheartj/ehz732.

24. Lopes RD, Leonardi S, Wojdyla DM, Vora AN, Thomas L, Storey RF, et al. Stent thrombosis in patients with atrial fibrillation undergoing coronary stenting in the AUGUSTUS trial. Circulation. 2020;141:781-3.

25. Giustino G, Chieffo A, Palmerini T, Valgimigli M, Feres F, Abizaid A, et al. Efficacy and safety of dual antiplatelet therapy after complex PCI. J Am Coll Cardiol. 2016;68:1851-64.

26. De Luca L, Musumeci G, Leonardi S, Gonzini L, Cavallini C, Calabrò $\mathrm{P}$, et al. Antithrombotic strategies in the catheterization laboratory for patients with acute coronary syndromes undergoing percutaneous coronary interventions. J Cardiovasc Med. 2017;18:580-9.

27. Fortuni F, Ferlini M, Leonardi S, Angelini F, Crimi G, Somaschini A, et al. Dual versus triple therapy in patients on oral anticoagulants and undergoing coronary stent implantation: a systematic review and meta-analysis. Int J Cardiol. 2018;273:80-7. 